\title{
Development of Integrated Operation and Management System for ICT-Based Plant Factory
}

\author{
Young-ChoonKim ${ }^{1}$ and Moon-Taek Cho ${ }^{2 *}$ \\ 'Department of Mechanical and Automotive Engineering, Kongju National University, 275 Budae-dong, \\ Seobuk, Chenonam-si, Chungnam, 31080, Korea; koreayckim59@kongju.ac.kr \\ 2Department of Electrical and Electronic Engineering, Daewon University College, 316 Daehak Road, \\ Jechen-si, Chungbuk, Province, 390-702, Korea; mtcho@mail.daewon.ac.kr
}

\begin{abstract}
Objectives: This study designs the growth analysis system of plant factory. Methods/Statistical Analysis: Based on core technologies to overcome the limitations of venue, light that is alternate to sunlight, automation, nutrient supply system, temperature, etc., as well as ICT such as sunlight generation and geothermal conditioning, in order to increase the freshness of agricultural products through ordered production and planned production. The plant factory has its purpose in controlling plant growth automatically and obtaining excellent productivity in a closed environment. Because plant factory is a very complex system with multiple sensors and control devices, the role of an integrated operation system that controls sophisticated and complicated operation of these devices is very important. Findings: It also creates new markets through the convergence of IT and BT industries and increased the convenience of agricultural industry through automatic control and robot development as well as the quality of the workplace. In addition, it provided urban citizens with an opportunity to experience and learn the entire process of plant growth, provided relaxation as an urban oasis for urban citizens who have been jaded by hectic urban life, prevented environmental pollution by conducting efficient recycling of resources, and established a system for producing and supplying various agricultural products stably throughout the year without being influenced by climate. Improvements/Applications: Existing integrated operation system of plant factory uses a device installed in plant factory for control and simple monitoring. Also, for monitoring and control of plant factory environment, a device that was actualized by the experience of the industrial developer was used. Notably, a method of automatic control of the developmental environment for existing integrated operation and management system for plant factory was in a static structure, where algorithm that does not consider crop properties are applied.
\end{abstract}

Keywords: Automatic Control, ICT, Plant Factory, Plant Growth, Sensors

\section{Introduction}

Reduction of poverty, growth of the middle class, educational innovation, and innovation in health management increases the power of the middle class, reducing the authority of government and corporations and including that of individuals. The world economy, a network of the whole world connected by resources, population, and economic power, cannot be controlled by the power of a single country anymore. The superpower of the United States is weakening and the power is being transferred to multinational leadership. The world's population will grow to 8.3 billion by 2010 , developing countries with young labor population will develop, economic reduction, lack of food, and increase in urban population due to aging population in advanced countries will cause social problems, increase in population will lead to $35 \sim 40 \%$ increase in demands for food, water, and energy, consumption of the middle class will expand to $50 \%$, climate change will reduce usability of important resources due to desertification, and lack of energy and agricultural water will cause lack of food ${ }^{1-4}$.

The concept of 6 th + industry, having its roots in Japan, is being newly recognized as the method for revi-

${ }^{*}$ Author for correspondence 
talizing industrial recession that slowed down after IT industries and for solving climate change. Traditionally, agricultural industry, a primary industry, grew agricultural products from nature. Secondary businesses, which introduced the concept of production to primary industries, brought specialization of plant seeds and expansion of businesses needed for production, such as plant and LED. Also, this will expand to include service including distribution, logistics, and consulting, and will further be converged with modern technologies such as IT, BT, GT, and CT to create a new market. Ultimately, mass production that overcomes nature and information network will converge with primary industry of agriculture to bring about a future agricultural society ${ }^{-\frac{4-8}{}}$.

As plant production system or artificial ecology, plant factory is a facility that controls growth environment artificially and produces agricultural products of same quality according to production plan, just like manufacturing factories. Such plant factories are currently not being actively promoted, due to current problems not only in high construction price but also in profitability that includes high operation expense, high production price, and lack of standardization in production technology. Methods for overcoming these are required, which can be solved by standardization of facility, production, and operation ${ }^{9-12}$.

This study designs growth analysis system of plant factory based on core technologies for overcoming of limitations of venue, light in alternative to sunlight, automation, nutrient supply system, temperature, etc., as well as ICT such as sunlight generation and geothermal conditioning, in order to increase freshness of agricultural products through ordered production and planned production. It also created new market through convergence with IT and BT industries and increased convenience of agricultural industry through automatic control and robot development as well as quality of workplace. In addition, it provided urban citizens with an opportunity to experience and learn the entire process of plant growth, prevented environmental pollution by providing relaxation as an urban oasis for urban citizens jaded by hectic urban life and by conducting efficient recycling of resources, and established a system for producing and supplying various agricultural products stably throughout the year without being influenced by climate. Although such plant production system for artificial ecology enables production of agricultural products with equal quality according to production plan on artificial control of growth environment and production automation, plant factory still has impending problems in terms of high construction expense, high operation expense, lack of exclusive breeds, lack of production technology for cultivated products, and stable profitability.

\section{ICT and Plant Factor}

Although human beings monitor plant factory, completed surrounded by artificial environment, there are no laborers, and computer and robots control the environment. Also, strange facilities grow the plants. In alternative to sun, LED shines light on plants to reduce harvesting time into half. Oxygen and carbon dioxide are emitted consistently to reduce emission that are emitted excessively in other businesses.

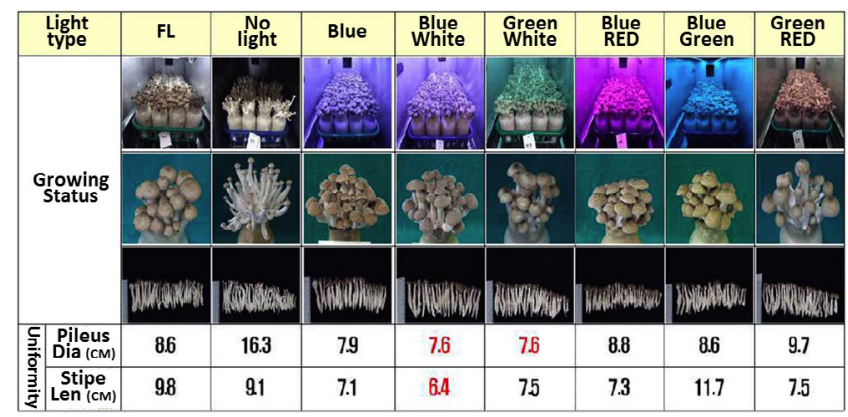

Figure 1. Change in mushroom growth by artificial light.

In plant factory, we artificially control the environment to mediate temperature, humidity, and carbon emission, and create an environment for optimal plant growth. Movement and monitoring on plants are all conducted through computer. One of such advantages is on various possibilities. Cultivation is possible regardless of venue such as underground or shipping vessels. However, tasks are still to be overcome. Although renewable energy, such as sun, is need for stable and consistent energy supply for conditions without consistent climate conditions, such as the Middle East, the cost stays very expensive.

The biggest problem is that plant factory requires much energy and electricity for cooling system. A technology that can reduce energy must precede success of plant factory.

Light in alternative to sunlight is critical for plant growth. Growth, flowering, and fruition are done according to strength and duration of light. There are three types of light: sunlight, artificial light, and mixed light. Artificial light divides into cathode ray fluorescent light, high-volt- 
age natrium, LED, etc. Recently, interest in LED, with low electricity consumption rate, is increasing. Figure 1 shows change in mushroom growth by artificial light and Figure 2 shows change in cultivation of functional components due to control of LED wavelength.

Figure 3 shows process of automation system. Development of automation and robotization technology by process of plant cultivation is actively being conducted in order to increase work efficiency and productivity through process of automatic facilities. This leads to reduction in labor force, preventing pollution from workers and utilization of senior workforce and automatic facilities.
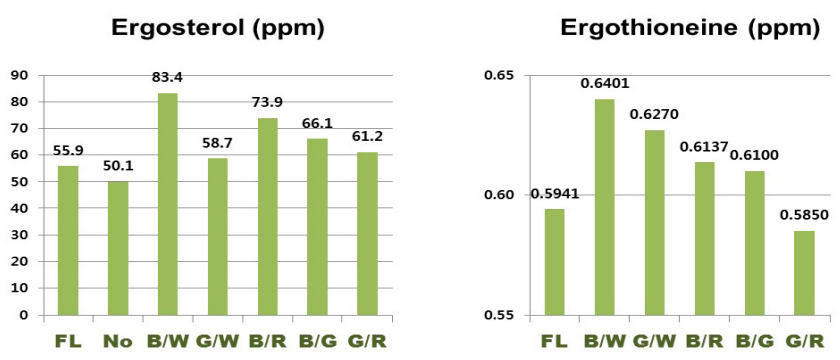

Figure 2. Change in cultivation of functional components due to control in wavelength of LED light.

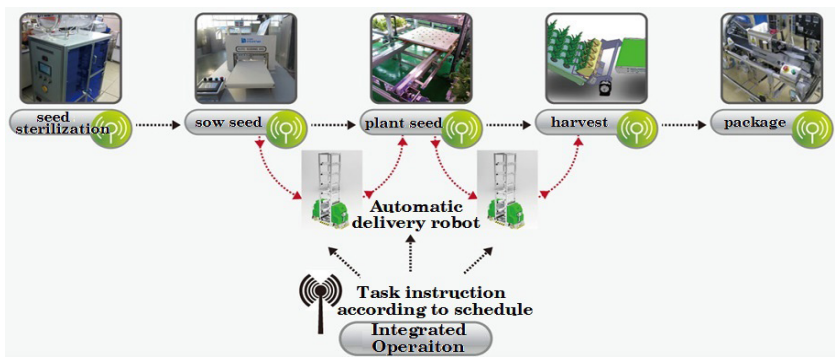

Figure 3. Process of automatic facility.

Nutrient cultivation is divided by method of supplying nutrients. It is chosen by plant properties, facilities, and quantity of water required. For circulatory nutrient, $\mathrm{Ph}, \mathrm{EC}$, temperature, and dissolved oxygen are managed. Nutrient supply system creates nutrients through growth steps by crops, conducting management on period of nutrient supply and on creation of circulatory nutrient. Figure 4 shows nutrient supply system.

Figure 5 shows factory-style plant production system for artificial ecology, a new agricultural method which produces agricultural products just like manufactured goods through control of growth environment and production automation in a closed environment. This system is a new agricultural technique that plans and produces agricultural products of equivalent sizes just like manufactured goods. Plant factory consists of smart lighting, intelligent plant cultivation system, monitor/control network, and plant factory management system. Smart lighting was applied for energy efficiency, and intelligent plant cultivation system was constructed under standardized module structure. Monitoring/control network applied with Wireless/USN networking was applied. In addition, plant factory management system for plant factory ERP is included Nut.

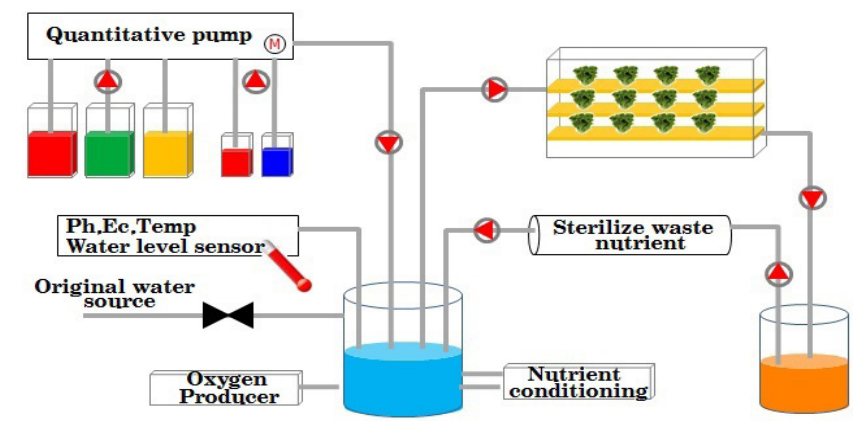

Figure 4. Nutrient supply system.

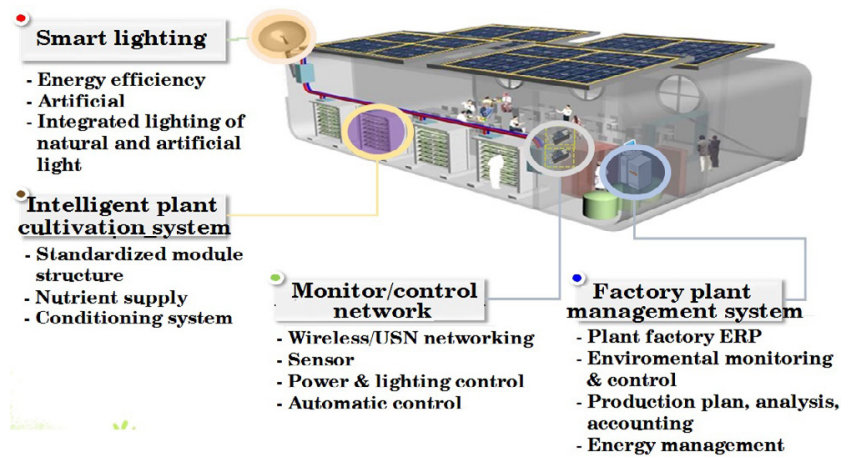

Figure 5. Plant production system.

\section{System Architecture}

When basic framework of plant factory system for development of plant factory system is established based on Event Driven Architecture (EDA), high efficiency and large-scale management becomes possible. EDA, Event Driven Architecture, consists of Event -system response on an event-, which is loosely coupled with unit system, enabling services by developed unit system. Development of a new system results in loose connection, the delivery of EVENT, with a new system or flexible connection with a new system.

Figure 6 shows structure of Publish/Subscribes for EDA. 


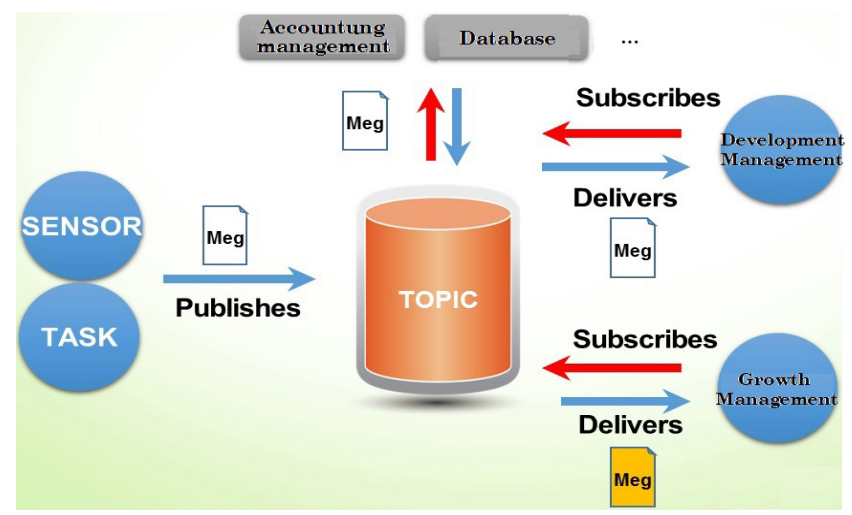

Figure 6. Structure of EDA publish/subscribes.

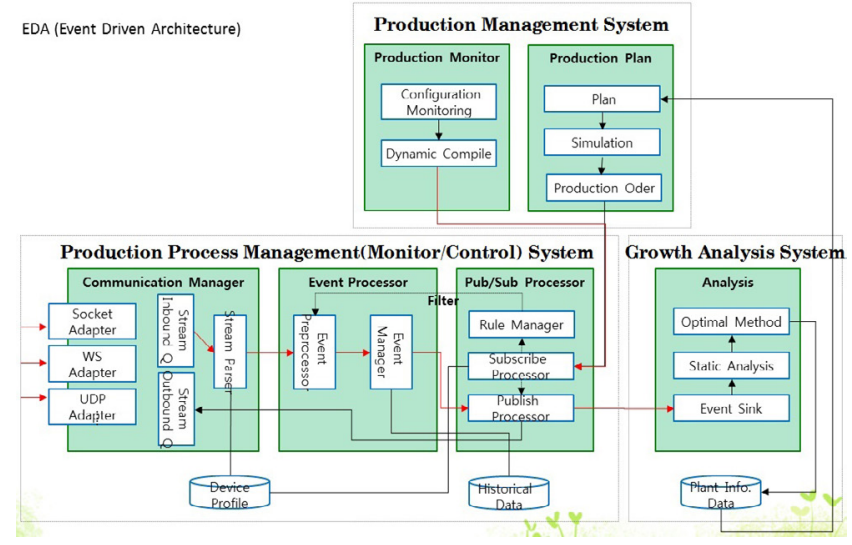

Figure 7. System architecture flow chart.

Figure 7 shows an architecture flow chart based on EDA. Integrated management system consists of three structures, and 3 unit systems of development management system, growth management system, and growth analysis system are loosely connected in the form of PubSub.

\section{Measurement of Plant Growth}

Growth measurement measures morphological measurement and physiological function. When measuring growth, stress on plant due to real-time measurement must be minimized. Figure 8 shows growth measurement sensor.

Information is obtained by loading sensor on satellite, airplane, etc., in order to measure status of crops that grow in wide area. Measure magnitude of reflection for light with multiple wave lengths using sensor in order to measures growth status of crops.

Measurement of vegetation index has been suggested in order to infer vegetation status on ground based on satellite data. This is one of the factors that show physiological conditions and properties of plant quantity, seasonal changes, and vegetation. Indexes related to vegetation are used as indexes related to relative distribution and activity of green plants, Leaf Area Index (LAI), quantity of chlorophyll and quantity of absorbed radiation from photosynthesis (APAR), etc., on ground. They have close relationship with reflective properties of wavelengths of visible ray spectrum and far-red spectrum. A popular vegetation index is Normalized Difference Vegetation Index (NDVI).

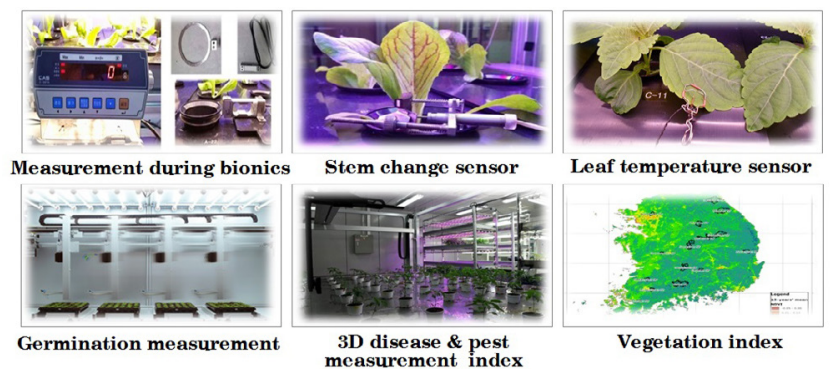

Figure 8. Growth measurement sensor.

NDVI is used to minimize the effect of difference in observation conditions, such as observation area or season, when handling earth-scale resource problems. NDVI uses far-red wavelength and red wavelength and combines them together to produce equation 1 .

$$
\mathrm{NDVI}=\frac{\mathrm{NIR}-\mathrm{RED}}{\mathrm{NIR}+\mathrm{RED}}=\frac{\mathrm{R}_{850}+\mathrm{RED}_{650}}{\mathrm{R} 850-\mathrm{RED}_{650}}
$$

Growth measurement measures morphological measurement and physiological functions. When measuring growth, stress on plant due to real-time measurement must be minimized. Figure 9 shows light absorption and reflection effect of plant.

In order to predict quantity of crop production to facilitate planned production, video image and database on production quantity were devised, real-time video image for leaf area analysis program and middleware were developed, and database was used to conduct prediction analysis of production quantity.

For test condition, LED consisted of 1:1 combination 200 [ ] of red light $(630[\mathrm{~nm}])$ and blue light $(450[\mathrm{~nm}])$ to measure consumption for measurement of photosynthesis efficiency.

Also, quantity on photosynthesis demand and physiological metabolism for plant were measured for simultaneous cultivation of plants with similar photosyn- 
thesis efficiency. These were measured by plant height, plant width, and leaf area using video information; analysis was made through variable selection from the best subset regression and regression analysis from multivariable analysis.

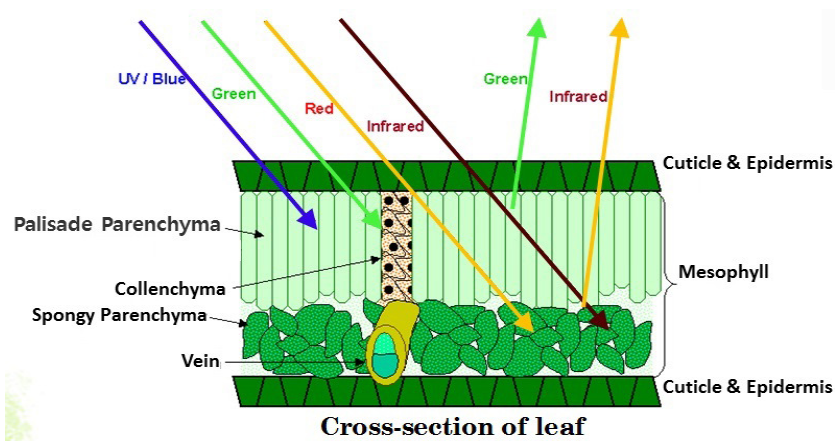

Figure 9. Light absorption and reflection effect of plant.

\section{Image Analysis}

Growth status was diagnosed by obtaining video from selective wavelength spectrum. Figure 10 shows LUV conversion of input video and LUV color analysis that extracts wavelength pertaining to UV value of pixels. Figure 11 and 12 shows classifications by use of algorithm such as k-means/SVM, pixel distribution analysis of LUV, IR histogram, and image analysis on distribution of reflection rate for selective wavelength acquisition.

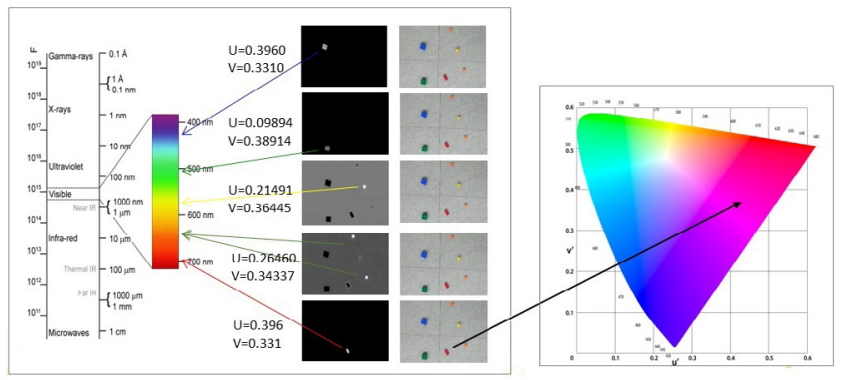

Figure 10. UV values according to colors of color video and pertaining wavelength expressions.

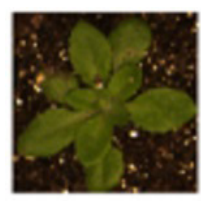

Original

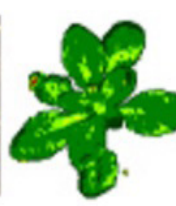

colour classified fluorescence $>700 \mathrm{~nm}$

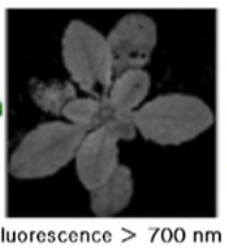

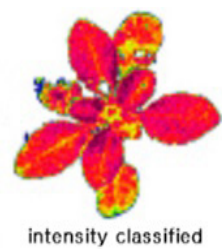

Figure 11. Classification on fluorescent strength of colors and chlorophyll.
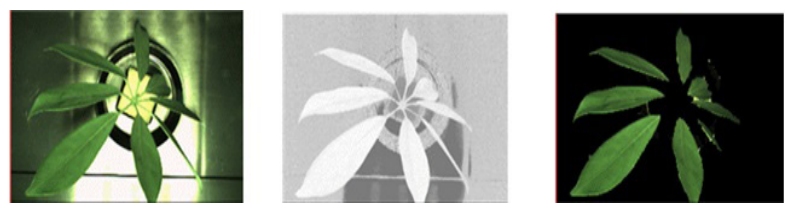

Figure 12. LUV segmentation.

\section{3D Measurement of Plant Using Stereo Camera}

Analysis of plant form by growth stage was used on germination and seedling. For image analysis, area algorithm that uses ratio of disparity values within segmented fields was developed, and distance information between pixels matching each other in two stereo images (left and right) were used to measure depth value as shown in Figure 13. Figure 14 shows disparity map image by stereo camera.
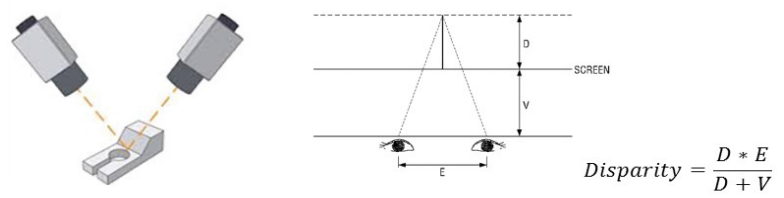

Figure 13. Measurement of depth using two images.
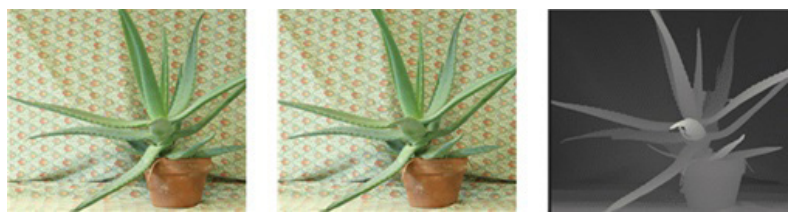

Figure 14. Disparity map image by stereo camera.

\section{Conclusion}

Existing integrated operation system of plant factory uses device installed in plant factory for control and simple monitoring. Also, for monitoring and control of plant factory environment, a device that was actualized by the experience of industrial developer was used. Notably, method of automatic control on developmental environment for existing integrated operation and management system for plant factory was in static structure, where algorithm that does not consider crop properties are applied. This is a disadvantage which leads to modification of the entire program when trying to apply development algorithm for different crops.

As a result, development of ICT-based integrated operation and management system presented in this paper produced the following result. 
- Increase freshness of agricultural products through ordered production and planned production,

- Create new market through convergence with IT and BT industries,

- Increased convenience of agricultural industry through automatic control and robot development as well as quality of workplace,

- Provide urban citizens with an opportunity to experience and learn the entire process of plant growth,

- Provide relaxation as an urban oasis for urban citizens who have been jaded by hectic urban life,

- Prevent environmental pollution conducting efficient recycling of resources, and

- Establish a system for producing and supplying various agricultural products stably throughout the year without being influenced by climate.

Although such plant production system for artificial ecology enables production of agricultural products with equal quality according to production plan on artificial control of growth environment and production automation, plant factory still has impending problems in terms of high construction expense, high operation expense, lack of exclusive breeds, lack of production technology for cultivated products, and stable profitability. Solving such problems will contribute to increase in competitiveness and profitability for agricultural units.

\section{References}

1. Analog Devices, 12-Bit R/D Converter with Reference Oscillator, Analog Devices; 2003. p. 1-25.

2. Analog Devices, Using the ADSP-2100 Family Analog Devices, 1990, 1, p.606.

3. Texas Instruments. TMS320F240 DSP Solution for Obtaining Resolver Angular Position and Speed, Application Report SPRA605, 2000.
4. Chung S, Kim HM, Kim SD. Formulation of Stable Bacillus Subtilis AH18 Against Temperature Fluctuation with Highly Heat-Resistant Endospores and Micropore Inoranic Carriers, Applied Microbiology Biotechnology. 2007; 76(1):217-24.

5. Idris EE, Iglesias DJ, Talon M, Borriss R. TryptophanDependent Production of Indole-3-Acetic Acid (IAA) Affects Level of Plant Growth Promotion, Bacillus Amyloliquefaciens FZB42, Molecular Plant-Microbe Interaction. 2007; 20(6):619-26.

6. Ellis G, Krah JO. Observer-based Resolver Conversion in Industrial Servo Systems. PCIM 2001 Conference; 2001. p. $1-6$.

7. Hoseinnezhad R, Harding P. A Novel Hybrid Angle Tracking Observer for Resolver to Digital Conversion, 44th IEEE Conference on Decision and Control and the European Control Conference; 2005. p. 7020-5.

8. Vijayaragavan E, Gopal TV. Biomechanical Modeling of Human Foot using Finite Element Methods, Indian Journal of Science and Technology. 2016 Aug; 9(31):1-5.

9. Javadi MA, Ghomashi H. Thermodynamics Analysis and Optimization of Abadan Combined Cycle Power Plant, Indian Journal of Science and Technology. 2016 Feb; 9(7):1-12.

10. Kemiki O, Baba J, Sanusi Y, Ighalo J. An Assessment of Land use Change as Influenced by an Industrial Property in Ewekoro between 1986 and 2015 using Remote Sensing Technique: Implications for Estate Surveyors and Valuers, Indian Journals of Science and Technology. 2016 May; 9(18):1-11.

11. Dastjerdi NB. Analyzing the Opportunities and Challenges to use of Information and Communication Technology Tools in Teaching-Learning Process, Indian Journal of Science and Technology. 2016 Feb; 9(6):1-8.

12. Nair PR, Anbuudayasankar SP. An Investigation on the Benefits of ICT Deployment in Supply Chain Management (SCM), Indian Journal of Science and Technology. 2016 Aug; 9(30):1-7. 